\title{
Fifteen-year experience with minimally invasive approach for reoperations involving the mitral valve
}

\author{
Joseph M. Arcidi, Jr, MD, Evelio Rodriguez, MD, Joseph R. Elbeery, MD, L. Wiley Nifong, MD, \\ Jimmy T. Efird, PhD, and W. Randolph Chitwood, Jr, MD
}

\begin{abstract}
Objective: Reoperative sternotomy to address mitral valve pathology carries substantial risk, especially with patent bypass grafts or an aortic valve prosthesis. We previously reported our early experience with minimally invasive right thoracotomy and peripheral cannulation as an alternative strategy, and we recently reviewed our cumulative 15-year hospital outcomes with this approach.
\end{abstract}

\begin{abstract}
Methods: Between June 1996 and April 2010, we performed right minithoracotomy for reoperations involving the mitral valve on 167 patients, $85(51 \%)$ of these since 2006 . Seventy-one percent had undergone previous coronary artery bypass grafting and $38 \%$ a previous valve procedure. Fibrillatory arrest was used in $77 \%$ and aortic clamping and root cardioplegia in $23 \%$. Nineteen procedures were performed with robotic assistance.
\end{abstract}

Results: Mitral repair frequency increased during each 5-year interval of our experience (1996-2000, 43\%; $2001-2005,53 \% ; 2006-2010,72 \% ; P=.019)$, including $80 \%$ of native mitral valves without stenosis. Concomitant procedure frequency, most commonly atrial fibrillation ablation, also increased during each 5-year interval $(0 \%, 21 \%, 48 \% ; P<.0001)$. Thirty-day mortality was $3.0 \%(5 / 167), 0 \%$ since 2005 . There were no conversions to sternotomy or aortic dissections. Stroke, in 2.4\% (4/167), was statistically unrelated to fibrillatory arrest. Increased New York Heart Association functional class (odds ratio, 5.6; 95\% confidence interval $1.1-27.8 ; P=.037$ ) was the only independent predictor of mortality in multivariable analysis.

Conclusions: Our updated experience confirmed the effectiveness of minimally invasive right thoracotomy to treat mitral pathology while avoiding reoperative sternotomy risk. We found fibrillatory and cardioplegic arrest methods to be safe myocardial preservation strategies with this approach. (J Thorac Cardiovasc Surg $2012 ; 143: 1062-8)$

Although the principal interest in minimally invasive mitral valve approaches has been among patients undergoing elective operations in the primary setting, the avoidance of reoperative sternotomy may represent a more compelling indication for patients with previous cardiac operations. Reoperative sternotomy risks injury to patent coronary artery bypass grafts and right-sided cardiac chambers, particularly in patients with pulmonary hypertension. In addition, a preexisting aortic valve prosthesis may hamper mitral exposure when approached through a sternotomy.

These risks are substantial but are rarely quantified, with the preponderance of reports on reoperations for mitral

\footnotetext{
From the Department of Cardiovascular Sciences, East Carolina Heart Institute, and the Brody School of Medicine at East Carolina University, Greenville, NC.

Disclosures: Evelio Rodriguez reports consulting fees from CardioNet and lecture fees from Intuitive Surgical, ATS Medical, and Medtronic. L. Wiley Nifong reports lecture fees from Intuitive Surgical. W. Randolph Chitwood, Jr, reports lecture fees from Intuitive Surgical and Edwards Lifesciences and grant support from Altricure. The other authors have nothing to disclose with regard to commercial support.

Received for publication April 4, 2011; revisions received June 9, 2011; accepted for publication June 28, 2011; available ahead of print Aug 8, 2011

Address for reprints: W. Randolph Chitwood, Jr, MD, Department of Cardiovascular Sciences, East Carolina University, 600 Moye Blvd, Greenville, NC 27858 (E-mail: wrc.reviews@gmail.com).

0022-5223/\$36.00

Copyright (c) 2012 by The American Association for Thoracic Surgery doi:10.1016/j.jtcvs.2011.06.036
}

pathology focusing purely on reoperations after previous mitral repair or replacement. ${ }^{1-8}$ The report of Lytle and colleagues ${ }^{9}$ stands alone as having reviewed all reoperations involving a valve and demonstrated that a previous aortic valve replacement was the most pronounced risk factor when approaching native or prosthetic mitral disease, carrying a mortality of $26 \%$. Likewise, specifically addressing patients with previous coronary artery bypass grafting (CABG) who required native or prosthetic mitral operations, Izhar and associates ${ }^{10}$ and Jamieson and coworkers ${ }^{11}$ identified operative risks of $8.8 \%$ and $14 \%$, respectively. Although the Society of Thoracic Surgeons (STS) risk calculator ${ }^{12}$ suggests a lower risk than these series, the nonoperative treatment of patients deemed to carry excessive risk suggests that the computed risk likely represents an underestimate.

Since 1996, we have recognized this challenging scenario as an appropriate direction for a minimally invasive approach. In 2004, we reported on a 38-patient retrospective experience with a $5-\mathrm{cm}$ right anterior thoracotomy to approach the mitral valve after previous cardiac operations. ${ }^{13}$ We compared this cohort with 33 patients undergoing reoperative sternotomy and demonstrated a lower red blood cell transfusion rate, shorter intubation duration, and a shorter postoperative stay with the minimally invasive approach. Mitral repair was performed in only $42 \%$ of 


\section{Abbreviations and Acronyms \\ $\mathrm{CABG}=$ coronary artery bypass grafting \\ NYHA $=$ New York Heart Association \\ STS $=$ Society of Thoracic Surgeons}

patients. The operative mortality was $5.7 \%$, similar to that reported in a larger series by the Leipzig group. ${ }^{14}$ Because our minimally invasive mitral experience has matured to encompass more than 1000 cases, we evaluated the success of this approach in an updated series of reoperative patients.

\section{MATERIALS AND METHODS}

The study was approved by the institutional review board, and the requirement for individual patient consent was waived. The hospital records of all cardiac surgical patients at our center have been abstracted in a database for STS reporting. This database was queried for all patients undergoing minimally invasive mitral valve procedures as cardiac reoperations, beginning with the first patient in 1996. Patients were excluded if the only previous cardiac operation was a coarctation procedure performed through a left thoracotomy or a pericardial drainage procedure. Current operations performed through a partial sternotomy were excluded. Primary or reoperative mitral repair or replacement procedures were included, whether performed singly or in combination with tricuspid repair or replacement, atrial septal defect closure, or atrial fibrillation ablation. There were no exclusions for enhanced surgical acuity. Among more than 1000 patients undergoing minimally invasive mitral valve operations between June 1996 and April 2010, a total of 167 patients met these criteria.

\section{Preoperative Characteristics}

During the 15-year study period, 14 procedures $(8 \%)$ were performed between 1996 and 2000, $68(41 \%)$ between 2001 and 2005, and 85 $(51 \%$ ) between 2006 and 2010 (Figure 1, A). The preoperative characteristics are listed in Table 1 . The age of patients ranged from 35 to 86 years, with $45 \%$ of patients 70 years old or older. Eighty-eight percent of patients had undergone 1 previous cardiac operation, most frequently (71\%) involving CABG. A previous aortic, mitral, or tricuspid valve procedure had been performed in 64 patients $(38 \%)$.

Elective operations were performed in $90.4 \%$ of patients. The mean New York Heart Association (NYHA) functional class was $2.6 \pm 0.8$, with $54 \%$ of patients in NYHA class III or IV. The left ventricular ejection fraction was $49 \% \pm 12 \% ; 20$ patients $(12 \%)$ had an ejection fraction of $35 \%$ or less. Mitral regurgitation was moderate to severe in $95 \%$. Thirteen patients had bioprosthetic mitral stenosis (11 with previous mitral repairs), and 7 had native mitral stenosis. Fifty-four patients had moderate or severe tricuspid regurgitation.

\section{Surgical Technique}

The fundamental technique for minimally invasive mitral valve procedures performed as reoperations has been described previously. ${ }^{13}$ Operations were performed with Swan-Ganz catheterization and continuous transesophageal echocardiographic monitoring; 3-dimensional echocardiography has been used since 2008 . After percutaneous insertion of a superior vena caval cannula through the right internal jugular vein, patients were positioned supine with the right side of the chest elevated $30^{\circ}$. Previous right thoracotomy was deemed a contraindication to a minimally invasive mitral approach. A 5-cm anterolateral right minithoracotomy in the 4th intercostal space provided working access, and a separate access port was used to introduce a videoscope (Olympus Surgical, Center Valley, Pa).
Specialized elongated-shaft instruments were used (Geister, Inc, Plymouth, Mass). The da Vinci S system (Intuitive Surgical, Inc, Sunnyvale, Calif) was used for robotic procedures, with right and left instrument arms placed in 3rd and 5th intercostal space ports and a left atrial retractor through an anterior 3rd or 4th intercostal space port. When aortic clamping was performed, a Chitwood transthoracic aortic clamp (Scanlan International, Inc, St Paul, Minn) was placed posterior to the midaxillary line in the 2nd or 3rd intercostal space. The chest cavity was flooded with carbon dioxide to mitigate intracavitary air. Cannulation for cardiopulmonary bypass was performed through a 2- to $3-\mathrm{cm}$ oblique infrainguinal incision. In patients with severe descending aortic or iliofemoral atherosclerosis, the right axillary artery was cannulated. Vacuum-assisted venous drainage was used during cardiopulmonary bypass, with systemic cooling to $28^{\circ} \mathrm{C}$. Hypothermic $\left(26^{\circ} \mathrm{C}\right)$ fibrillatory arrest, when used, was induced and maintained with a fibrillator or, more recently, a pacing Swan-Ganz catheter (Edwards Lifesciences LLC, Irvine, Calif). Alternatively, antegrade cardioplegia was delivered through a transthoracic catheter. Retrograde cardioplegia was infrequently used.

Standard mitral repair and replacement techniques were used. Annuloplasty rings (Simulus FLX-C; ATS Medical, Inc, Minneapolis, Minn; Cosgrove-Edwards Annuloplasty System; Edwards Lifesciences) were secured with 2-0 Cardioflon suture (Péters Surgical, Bobigny, France) or nitinol clips (Coalescent Surgical, Inc, Sunnyvale, Calif). Mitral replacement was performed with posterior leaflet sparing. Deairing was accomplished with Valsalva maneuvers and volume filling of the heart, through a transmitral vent frustrator catheter that exited through the atriotomy closure and, when feasible, through an aortic root vent. In patients undergoing concomitant tricuspid repair, a transseptal approach was used for mitral valve exposure. Linear ablation for atrial fibrillation was performed in most patients with cryothermy (CryoMaze; ATS Medical). We have preferred a biatrial lesion set for long-standing persistent and permanent atrial fibrillation.

\section{Statistical Methods}

Preoperative characteristics, intraoperative data, and postoperative outcome variables were recorded with STS Database definitions. ${ }^{15}$ Continuous variables were expressed as mean $\pm \mathrm{SD}$. We performed univariate analyses of 13 preoperative and intraoperative risk factors for mortality, including age, sex, surgical urgency, 5-year surgical experience interval, number of previous operations, NYHA functional class, mitral pathophysiology, mitral procedure, concomitant procedure, myocardial preservation method, and intervals of fibrillatory and cardioplegic arrest and cardiopulmonary bypass. These analyses were performed with unpaired Student $t$ tests, $\chi^{2}$ tests, or Fisher Exact tests, as appropriate. Means tested over intervals of surgical experience were compared with analysis of variance (SAS version 9.2; SAS Institute Inc, Cary, NC). Multivariable log-normal plots were used to assess underlying normality and heteroskedasticity of the data. When appropriate, normalizing or variance stabilizing transformations were applied to the data. Model lack of fit for multivariable logistic regression analyses was assessed with the Hosmer-Lemeshow procedure, which compares observed and expected event rates in subgroups of the model population.

\section{RESULTS}

Among the 167 patients, 103 (62\%) underwent mitral valve repair. The frequency of repair increased during each 5-year interval $(1996-2000,43 \%$; 2001-2005, 53\%; $2006-2010,72 \% ; P=.019)$; this and additional interval trends are depicted in Figure 1 ( $B$ through $E$ ). Repair procedures involved annuloplasty alone in 60 patients. Isolated annuloplasty repairs were more frequent than more complex repairs among patients whose previous operation involved CABG $(92 \%$ vs $67 \% ; P=.0018)$. Complex repairs, including leaflet and chordal procedures, were 


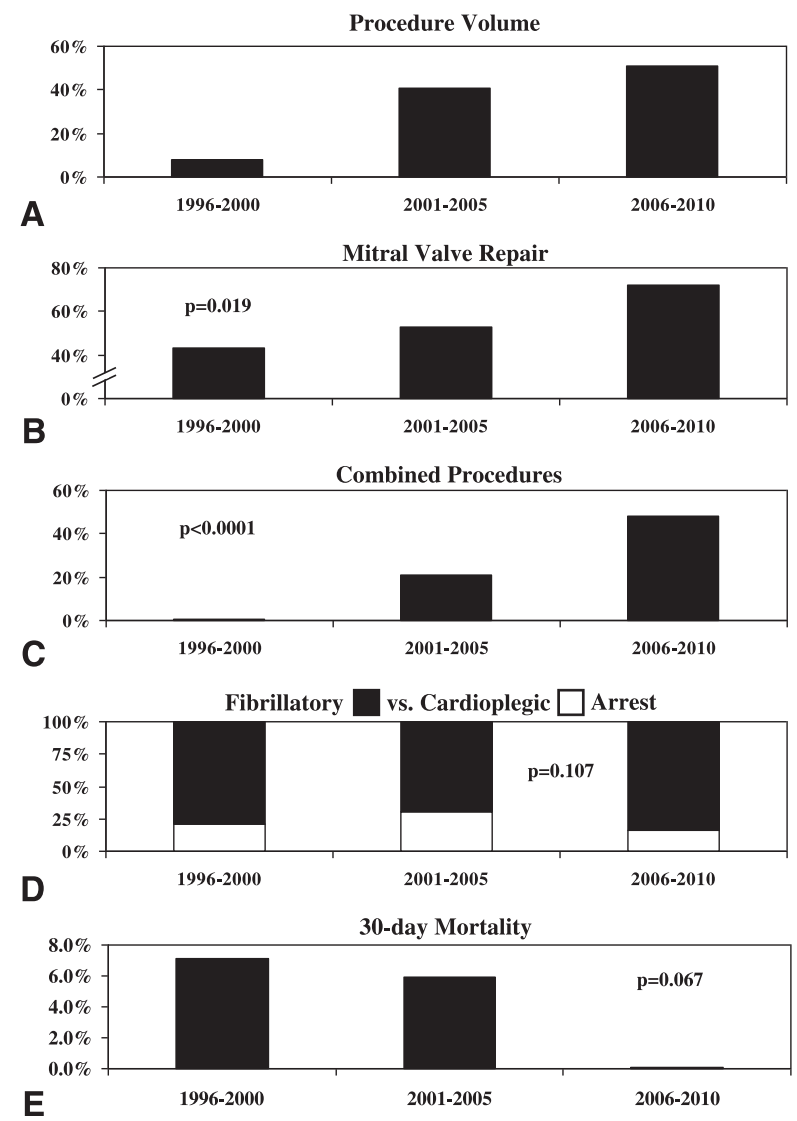

FIGURE 1. Fifteen-year trends in minimally invasive reoperations involving the mitral valve by 5 -year interval. A, Procedure volume increased by interval, with $51 \%$ of procedures performed in the last 5 years. B, Frequency of mitral valve repair increased by interval, to $72 \%$ in the last 5 years. C, Frequency of procedures (atrial fibrillation ablation, tricuspid valve repair or replacement, atrial septal defect or patent foramen ovale closure) combined with mitral valve operation increased by interval, to $48 \%$ in the last 5 years. D, Fibrillatory arrest $\left(26^{\circ} \mathrm{C}\right)$ was more commonly used than aortic clamping and cardioplegia in each interval, an increasing trend. E, Trend toward decreasing 30-day mortality by interval, with no deaths within 30 days in the last 5 years.

performed in 43 patients, with papillary muscle repair in 1 patient. The mean annuloplasty ring diameter was $31 \pm 3$ $\mathrm{mm}$; the ring diameter was smaller for isolated annuloplasty repairs ( $29 \pm 2 \mathrm{~mm}$ vs $33 \pm 4 \mathrm{~mm}, P<.0001)$. Mitral reconstruction did not involve annuloplasty in 3 patients.

Mitral replacement was performed in 64 patients, and in $33(52 \%)$ of these cases a bioprosthesis was implanted. The mean labeled valve size was $27 \pm 2 \mathrm{~mm}$. Replacement was performed for $25 \%$ of native valves and for $75 \%$ of patients with a previous mitral procedure. Procedures in native and previously operated mitral valves are outlined in Table 2 .

Robotic assistance with the da Vinci system was used in 19 of the 167 mitral procedures $(11.4 \%)$. This included 4 isolated annuloplasty repairs, 10 complex repairs, and 5 replacements. All but 1 of the robotic procedures was performed in the most recent 5-year interval.
TABLE 1. Preoperative characteristics $(n=167)$

\begin{tabular}{|c|c|}
\hline$\overline{\text { Age }(y, \text { mean } \pm S D)}$ & $66.9 \pm 10.7$ \\
\hline Age $\geq 70 y$ & $75(45 \%)$ \\
\hline Sex (male) & $103(62 \%)$ \\
\hline \multicolumn{2}{|l|}{ Previous operations } \\
\hline 1 & $147(88 \%)$ \\
\hline 2 & $19(11.4 \%)$ \\
\hline 3 & $1(0.6 \%)$ \\
\hline \multicolumn{2}{|l|}{ Previous operations (type) } \\
\hline Isolated CABG & $94(56 \%)$ \\
\hline $\mathrm{CABG}$ and valve & $24(14 \%)$ \\
\hline Aortic valve replacement & $19(11 \%)$ \\
\hline MV repair & $34(20 \%)$ \\
\hline MV replacement & $7(4 \%)$ \\
\hline \multicolumn{2}{|l|}{ Surgical timing } \\
\hline Elective & $155(93 \%)$ \\
\hline Urgent & $10(6 \%)$ \\
\hline Emergency & $2(1.2 \%)$ \\
\hline NYHA functional class (mean \pm SD) & $2.6 \pm 0.8$ \\
\hline NYHA class IV & $23(14 \%)$ \\
\hline Ejection fraction $(\%$, mean $\pm \mathrm{SD})$ & $49 \pm 12$ \\
\hline \multicolumn{2}{|l|}{ Mitral regurgitation } \\
\hline Moderate & $21(12 \%)$ \\
\hline Severe & $138(83 \%)$ \\
\hline Mitral stenosis & $20(12 \%)$ \\
\hline \multicolumn{2}{|l|}{ Tricuspid regurgitation } \\
\hline Moderate & $35(24 \%)$ \\
\hline Severe & $19(13 \%)$ \\
\hline
\end{tabular}

Tricuspid repair was combined with mitral repair in $5 \mathrm{pa}-$ tients and with mitral replacement in 4 . Concomitant mitral and tricuspid replacement was performed in 1 patient. Forty-five patients $(27 \%)$ underwent concomitant cryoablation, radiofrequency, or microwave ablation for atrial fibrillation. Closure of an atrial septal defect or patent foramen ovale was performed in 6 patients. The frequency of combined procedures increased during each successive 5-year interval (1996-2000, 0\%; 2001-2005, 21\%; 2006-2010, 48\%; $P<.0001)$.

\section{Myocardial Protection}

Fibrillatory arrest at $26^{\circ} \mathrm{C}$ was used for myocardial preservation in 129 patients $(77 \%)$. Aortic occlusion and cardioplegic arrest was used in 39 patients $(23 \%)$, with a transthoracic clamp placed in all but 1 patient. Both methods were required in 1 patient. An interval of hypothermic circulatory arrest, with a median duration of 5 minutes, was required in 6 patients because of aortic valve regurgitation. Fibrillatory arrest was used significantly more often than cardioplegic arrest among 118 patients who had previously undergone CABG $(90 \%$ vs $10 \% ; P<.0001)$ but not among 19 who had previous aortic valve replacement $(63 \%$ vs $37 \% ; P=.120$ ). There has been a trend toward increased use of fibrillatory arrest in recent years, involving $84 \%$ of 
TABLE 2. Native versus previously operated mitral valves $(n=167)$

\begin{tabular}{lc}
\hline Native mitral valve & 126 \\
Repair procedure & $95(75 \%)$ \\
Annuloplasty only & 59 \\
Complex repair & 35 \\
Papillary muscle repair & 1 \\
Postoperative mitral regurgitation & \\
None or trace & 87 \\
Mild & 8 \\
Replacement indication & $31(25 \%)$ \\
Mitral regurgitation & 24 \\
Mitral stenosis & 7 \\
Previous mitral repair & 34 \\
Repeat repair procedure & $7(21 \%)$ \\
Annuloplasty only & 1 \\
Complex repair & 6 \\
Postoperative mitral regurgitation & \\
None & 6 \\
Mild & 1 \\
Replacement & $27(79 \%)$ \\
Previous mitral replacement & 7 \\
Repair paravalvular leak & 1 \\
Repeat replacement & 6 \\
\hline
\end{tabular}

All data represent numbers of patients.

cases during the interval of 2006 to 2010, and approaching significance relative to previous intervals $(P=.107)$.

The mean fibrillatory arrest and crossclamp times were $110 \pm 42$ minutes and $113 \pm 32$ minutes (ranges, 39-284 and 36-170 minutes), respectively, and neither the mean fibrillatory arrest nor the mean crossclamp time changed significantly during each 5-year interval. Among 63 patients undergoing isolated mitral repair, fibrillatory arrest (52 patients) and cardioplegic arrest (11 patients) times were similar (93 \pm 33 minutes vs $105 \pm 29$ minutes; $P=.259)$. The mean duration of cardiopulmonary bypass was $167 \pm 51$ minutes (range, 78-371 minutes).

\section{Complications}

There were no aortic dissections or conversions to median sternotomy. One patient required resumption of cardiopulmonary bypass for successful control of bleeding from an antegrade cardioplegia cannulation site. An intra-aortic balloon pump was inserted intraoperatively in 3 patients. Five patients $(3.0 \%)$ died within the 30-day postoperative period; however, we have not observed any 30-day postoperative mortality within the past 5 years. The causes of death were cardiac failure in 1 patient, respiratory failure in 2 (1 with pulmonary hemorrhage), cerebrovascular accident in 1 , and multisystem organ failure in 1. Major postoperative complications occurred among 17 of the surviving patients $(10.1 \%)$, including reoperation for bleeding in 5 patients, stroke in 3, respiratory failure in 9, and renal failure in 6 (with 5 requiring dialysis).

There was no relationship on univariate analyses between the cerebrovascular accidents in 4 patients $(2.4 \%)$ and use of fibrillatory or cardioplegic arrest, age, NYHA functional class, surgical urgency, a previous valve procedure, previous CABG, duration of perfusion, or a concomitant procedure. Eighteen patients had pneumonia develop, with 5 of these occurrences in the right lung. Univariate analyses showed no association between pneumonia and age, NYHA functional class, robotic assistance, or a concomitant procedure. One patient acquired a localized infection at the thoracotomy wound. Sixty-four patients (38\%) received no transfusions. Among transfused patients, the mean quantity of packed red blood cells received was $2.9 \pm 3.9$ units (median 2.0 units). The median duration of ventilator support was 11.4 hours, and the median postoperative stay was 6.0 days.

\section{Predictors of Mortality}

Thirty-day mortality was associated with increased NYHA functional class $(3.4 \pm 0.9$ vs $2.6 \pm 0.8$; $P=.027$ ). Among 23 patients in NYHA class IV, the operative mortality was $13.7 \%$. Mortality was not related to ejection fraction, nonelective status, or myocardial preservation method. Lower mortality, with the trend approaching statistical significance, was observed in each successive interval of experience (1996-2000, 7.1\%; 2001-2005, 5.8\%; 2006-2010, $0 \% ; P=.069)$. Only NYHA functional class was identified as an independent predictor of mortality with multivariable logistic regression (odds ratio, 5.6; $95 \%$ confidence interval, $1.1-27.8 ; P=.037)$.

\section{DISCUSSION}

The optimal approach to the mitral valve in patients with a previous sternotomy is controversial, particularly for patients not requiring concomitant $\mathrm{CABG}$ or aortic valve replacement. The advantage of a right thoracotomy of varying size relative to reoperative sternotomy has been avoidance of injury related to sternal reentry or dissection. Svensson and associates, ${ }^{16}$ however, in a review of a Cleveland Clinic experience, compared 2444 reoperative sternotomy cases with 80 right thoracotomy cases and noted equivalent mortalities of $6.7 \%$ and $6.3 \%$, respectively, for the approaches. Additionally, in their series, a right thoracotomy approach was less likely to achieve a mitral repair and carried a $7.5 \%$ cerebrovascular accident rate.

Our report reflects the maturation of an effort beginning in 1996 to decrease the morbidity of a right thoracotomy without compromising the intent to repair suitable mitral valve pathology. In our initial report ${ }^{13}$ extending to the middle of 2003, mortality was $5.7 \%$ with video-assisted right minithoracotomy, but replacements outnumbered repairs. The additional experience since that report, provided by our primary mitral repair population, has contributed to the progress of patients undergoing reoperative procedures. Our 30-day mortality for the cumulative series has been $3.0 \%$, with no deaths within 30 days occurring in the past 
5 years, and the frequencies of repair are $62 \%$ cumulatively and $72 \%$ during the past 5 years.

The success of our minimally invasive strategy hinges on its effectiveness in addressing both native and previously operated mitral valves. When approaching a native valve after previous sternotomy, the distinction between a primary minimally invasive approach is exposure; once obtained, the goal of achieving repair whenever feasible is the same as during a primary operation. In this series, mitral repair was performed on $75 \%$ of all native valves, and among all native valves without mitral stenosis the repair rate was $80 \%(95 / 119)$. In $62 \%$ of patients $(92 \%$ of whom had previous $\mathrm{CABG}$ ), repair involved annuloplasty alone, but leaflet repairs and an isolated papillary muscle reimplantation were performed in the remainder.

There is greater complexity at multiple sequences in patients with a previous mitral valve procedure, including the need to resect prosthetic material. A reoperative repair was able to be performed in $21 \%$ of 34 patients with previous mitral repair, similar to the outcome in all-cause reoperative median sternotomy reports. ${ }^{17,18}$ The minimally invasive approach did not impede the smaller number of repeated mitral replacements, with bioprostheses in most cases, and repair of a paravalvular leak in 1 patient. Although our experience has shown the minimally invasive approach to be effective and safe, our relatively infrequent and only recent adoption of da Vinci robotic assistance in the latest 5-year interval reflects a learning curve and underscores the greater complexity of reoperative procedures relative to primary procedures.

Another important distinction between primary and reoperative procedures during our 15-year experience has been an evolution in myocardial preservation strategy. One advantage of the right minithoracotomy approach is the avoidance of extensive dissection, and the use of hypothermic fibrillatory arrest circumvents the need for placement of a transthoracic clamp and cardioplegia delivery, especially with functional proximal coronary anastomoses. Our deairing strategy, primarily with a transmitral vent catheter exiting through the left atriotomy closure, has been effective in minimizing cerebrovascular morbidity. In our series, the use of fibrillatory arrest in reoperative patients increased from $67 \%$ to $82 \%$ during the last decade, a trend that approached statistical significance. The choice of myocardial preservation did not affect mortality in our series, which compares favorably with other reports. $^{14,19}$ Fibrillatory arrest has been used with a similar frequency in Leipzig ${ }^{14}$ and has been the preferred approach for primary and reoperative patients at Vanderbilt University. ${ }^{20,21}$ Although another option, endoaortic balloon occlusion and cardioplegic arrest, has been favored by several groups, ${ }^{19,22,23}$ the simplicity and the reliability of myocardial preservation with fibrillatory arrest have reinforced its use in our practice.
The safety of fibrillatory arrest in our reoperative experience contrasts sharply with the findings from a STS Database series $^{24}$ of a 6-fold increase in stroke when using fibrillatory arrest with minimally invasive mitral repair. This specific finding notwithstanding, avoiding complications related to retrograde aortic perfusion and neurologic morbidity, including aortic dissection and atheroembolism, is paramount in the reoperative setting. No patients in our series sustained an aortic dissection. Moreover, with widespread adaptation to $17 \mathrm{~F}$ to $19 \mathrm{~F}$ femoral arterial cannulas, preoperative vascular screening, and strict transesophageal echocardiographic insertion guidance, aortic injury has occurred in $0.0 \%$ to $0.9 \%$ in comparable reoperative series. ${ }^{14,19,20,22,23}$ Our practice has been to screen selectively patients with a history of peripheral vascular disease, and we have extended such screening to elderly patients in recent years.

Stroke as a complication has been more reproducibly linked to retrograde arterial perfusion than to fibrillatory arrest in patients undergoing reoperative mitral valve procedures. Investigators at New York University ${ }^{25}$ identified retrograde perfusion as an independent risk factor for stroke, with an incidence of $10.9 \%$ versus $3.0 \%$ with central aortic cannulation and antegrade perfusion, their preferred strategy. Stroke was also roughly 3 times more frequent in the Cleveland Clinic series ${ }^{16}$ when using a right thoracotomy approach and retrograde femoral perfusion. The $2.4 \%$ incidence of permanent stroke in our series not only was statistically unrelated to our choice of fibrillatory arrest for myocardial preservation but also was within the $0.9 \%$ to $5.8 \%$ range observed in other minimally invasive reoperative reports ${ }^{14,19,21-23}$ and comparable with the $2.7 \%$ rate observed among patients undergoing reoperative sternotomy in the Cleveland Clinic experience. ${ }^{16}$ Axillary artery cannulation was used in $5.4 \%$ of patients in our series, and we concur with the practice at Vanderbilt ${ }^{20,21}$ of setting a low threshold for axillary cannulation for perfusion in patients with aortic atherosclerosis.

In addition to growth in procedural volume, a measure of our evolving confidence with the minimally invasive approach has been the performance of combined procedures in patients undergoing reoperation. Concomitant tricuspid repair, the maze procedure, and atrial septal defect closure have increased substantially during each 5-year interval of our experience $(P<.0001)$ to encompass $48 \%$ of procedures since 2006. The range of concomitant procedures in patients undergoing reoperation is limited relative to that afforded with transsternal exposure but is comparable to that achieved with a right minithoracotomy in primary operations. It is notable that our concomitant performance of the maze procedure in $26 \%$ of patients was equivalent in frequency to another recent reoperative minimally invasive mitral series from Leipzig. ${ }^{14}$ Given the broader access through a reoperative sternotomy, the increased rate at which a combined mitral-maze procedure appears to have 
been performed in minimally invasive reoperative series is somewhat paradoxic. One explanation for this disparity may be the enhanced interest in recent years in addressing coexisting atrial fibrillation. It is alternatively plausible that exposure for an endocardial ablation strategy is more facile through a lateral thoracotomy approach than is addressing the dissection required for either epicardial or endocardial approaches through a reoperative sternotomy.

Although we did not compare reoperative sternotomy and right minithoracotomy in this study, the only risk factor for mortality that manifested in the analyses, increased NYHA congestive heart failure class, has been seen with standard cardiac operations. Other variables particular to the minimally invasive approach, notably fibrillatory arrest, did not emerge as risk factors. Although these findings are not definitive, such a pattern suggests equivalent successes at our center of the minimally invasive approach and reoperative sternotomy.

Among nonfatal complications, however, we observed a $10.8 \%$ frequency of postoperative pneumonia. Twentyeight percent of these pneumonias were localized to the right lung and likely represent a complication specific to the minimally invasive approach. We are uncertain of the mechanism, aside from speculation regarding subtle trauma, but we note that an $8.8 \%$ rate of pneumonia or respiratory failure in reoperative minimally invasive cases has been observed by Casselman and colleagues. ${ }^{22}$

We demonstrated improved recovery parameters in our 2004 report ${ }^{13}$ with minimally invasive mitral reoperations relative to reoperative sternotomy. That analysis, unlike our updated series, excluded patients with more than 1 previous operation, emergency status, or combined procedures. Our cumulative 15-year experience demonstrated sustained favorable outcomes with our 2004 report in median ventilation time (11.4 vs 11.4 hours, respectively) and mean red blood cell transfusions ( 2.9 vs 2.9 units), with a modest impact in median postoperative hospital stay (6.0 vs 5.0 days) despite an increase in procedural complexity. The number of red blood cell transfusions and the ability to avoid transfusion in $38 \%$ of patients were observations similar to the Vanderbilt reoperative experience. ${ }^{21}$

The general interpretation of our updated experience, unlike the 2004 report, is limited in part by the absence of a defined reference group. In addition, our 15-year report describes an evolving technique, and this evolution likely entailed patient selection for a minimally invasive approach, as well as the choice of myocardial preservation and the inclusion of concomitant procedures.

In summary, our 15-year experience has demonstrated the utility of minimally invasive right thoracotomy to effectively address mitral valve pathology in reoperative patients while avoiding the risk of a repeat sternal reentry. Although this technique has been applied with increasing frequency as well as to greater patient complexity at our center, the associated mortality has decreased with time and appears favorable relative to historical studies involving reoperative sternotomy. Our expanded series confirms both fibrillatory and cardioplegic arrest to be useful preservation strategies, and minimally invasive right thoracotomy has supplanted sternotomy as our preferred approach to correct mitral regurgitation in the reoperative setting.

\section{References}

1. Tang GH, Maganti M, David TE, Feindel CM, Scully HE, Borger MA. Effect of prior valve type on mortality in reoperative valve surgery. Ann Thorac Surg. 2007;83:938-45

2. Luciani N, Nasso G, Anselmi A, Glieca F, Gaudino M, Girola F, et al. Repeat valvular operations: bench optimization of conventional surgery. Ann Thorac Surg. 2006;81:1279-83.

3. Potter DD, Sundt TM 3rd, Zehr KJ, Dearani JA, Daly RC, Mullany CJ, et al. Risk of repeat mitral valve replacement for failed mitral valve prostheses. Ann Thorac Surg. 2004;78:67-72.

4. de Almeida Brandão CM, Pomerantzeff PM, Souza LR, Tarasoutchi F, Grimberg M, Ramires JA, et al. Multivariate analysis of risk factors for hospital mortality in valvular reoperations for prosthetic valve dysfunction. Eur J Cardiothorac Surg. 2002;22:922-6.

5. Borger MA, Yau TM, Rao V, Scully HE, David TE. Reoperative mitral valve replacement: importance of preservation of subvalvular apparatus. Ann Thorac Surg. 2002;74:1482-7.

6. Jones JM, O'Kane H, Gladstone DJ, Sarsam MA, Campalani G, MacGowan SW, et al. Repeat heart valve surgery: risk factors for operative mortality. $J$ Thorac Cardiovasc Surg. 2001;122:913-8.

7. Gill IS, Masters RG, Pipe AL, Walley VM, Keon WJ. Determinants of hospital survival following reoperative single valve replacement. Can J Cardiol. 1999;15 1207-10.

8. Weerasinghe A, Edwards MB, Taylor KM. First redo heart valve replacement: a 10-year analysis. Circulation. 1999;99:655-8.

9. Lytle BW, Cosgrove DM, Taylor PC, Gill CC, Goormastic M, Golding LM, et al. Reoperations for valve surgery: perioperative mortality and determinants of risk for 1000 patients, 1958-1984. Ann Thorac Surg. 1986;42:632-43.

10. Izhar U, Daly RC, Dearani JA, Orszulak TA, Schaff HV, Mullany CJ. Mitral valve replacement or repair after previous coronary artery bypass grafting. Circulation. 1999;100(9 Suppl):II84-9.

11. Jamieson WRE, Burr LH, Miyagishima RT, Janusz MT, Fradet GJ, Lichtenstein SV, et al. Reoperation for bioprosthetic mitral structural failure: risk assessment. Circulation. 2003;108(Suppl 1):II98-102.

12. The Society of Thoracic Surgeons [Internet]. Chicago: The Society; c2005-10 [cited 7 Jun 2010]. Risk calculator and models, version 2.61. Available from: http://www.sts.org/quality-research-patient-safety/quality/risk-calculator-andmodels.

13. Bolotin G, Kypson AP, Reade CC, Chu VF, Freund WL Jr, Nifong LW, Chitwood WR Jr. Should a video-assisted mini-thoracotomy be the approach of choice for reoperative mitral valve surgery? J Heart Valve Dis. 2004;13:155-8.

14. Seeburger J, Borger MA, Falk V, Passage J, Walther T, Doll N, Mohr FW. Minimally invasive mitral valve surgery after previous sternotomy: experience in 181 patients. Ann Thorac Surg. 2009;87:709-14.

15. Haan CK, Breen LS. Adult cardiac surgery database training manual, version 2.61 [Internet]. Chicago: The Society of Thoracic Surgeons; c2011 [updated 10 Feb 2009; cited 7 Jun 2010]. Available from: http://www.sts.org/qualityresearch-patient-safety/national-database/database-managers/adult-cardiac-surgerydatabase/d.

16. Svensson LG, Gillinov AM, Blackstone EH, Houghtaling PL, Kim KH Pettersson GB, et al. Does right thoracotomy increase the risk of mitral valve reoperation? J Thorac Cardiovasc Surg. 2007;134:677-82.

17. Cerfolio RJ, Orszulak TA, Pluth JR, Harmsen WS, Schaff HV. Reoperation after valve repair for mitral regurgitation: early and intermediate results. J Thorac Cardiovasc Surg. 1996;111:1177-84.

18. Gillinov AM, Cosgrove DM, Lytle BW, Taylor PC, Stewart RW, McCarthy PM et al. Reoperation for failure of mitral valve repair. J Thorac Cardiovasc Surg. 1997;113:467-75.

19. Meyer SR, Szeto WY, Augoustides GT, Morris RJ, Vernick WJ, Paschal D, et al. Reoperative mitral valve surgery by the port access minithoracotomy approach is safe and effective. Ann Thorac Surg. 2009;87:1426-30. 
20. Umakanthan R, Leacche M, Petracek MR, Kumar S, Solenkova NV, Kaiser CA, et al. Safety of minimally invasive mitral valve surgery without aortic crossclamp. Ann Thorac Surg. 2008;85:1544-50.

21. Umakanthan R, Petracek MR, Leacche M, Solenkova NV, Eagle SS, Thompson A, et al. Minimally invasive right lateral thoracotomy without aortic cross-clamping: an attractive alternative to repeat sternotomy for reoperative mitral valve disease. J Heart Valve Dis. 2010;19:236-43.

22. Casselman FP, La Meir M, Jeanmart H, Mazzarro E, Coddens J, Van Praet F, et al. Endoscopic mitral and tricuspid valve surgery after previous cardiac surgery. Circulation. 2007;116(11 Suppl):I270-5.
23. Ricci D, Pellegrini C, Aiello M, Alloni A, Cattadori B, D'Armini AM, et al. Portaccess surgery as elective approach for mitral valve operation in re-do procedures. Eur J Cardiothorac Surg. 2010;37:920-5.

24. Gammie JS, Zhao Y, Peterson ED, O'Brien SM, Rankin JS, Griffith BP. J. Maxwell Chamberlain Memorial Paper for adult cardiac surgery. Less-invasive mitral valve operations: trends and outcomes from the Society of Thoracic Surgeons Adult Cardiac Surgery Database. Ann Thorac Surg. 2010;90:1401-10.e1.

25. Crooke GA, Schwartz CF, Ribakove GH, Ursomanno P, Gogoladze G, Culliford AT, et al. Retrograde arterial perfusion, not incision location, significantly increases the risk of stroke in reoperative mitral valve procedures. Ann Thorac Surg. 2010;89:723-30. 